thebatterycontrolled campaign was launched in Australia by the ACCC in partnership with Energiser and Kidsafe. This campaign increased awareness in consumers and suppliers of the risks associated with ingestion of lithiumcell button batteries.

\title{
06 REGULATORY APPROACH TO BUTTON BATTERIES
}

doi:10.1136/injuryprev-2012-040590i.6

Jamieson John, Burela Kathryn. Australian Competition and Consumer Commission, 23 Marcus Clarke Street, Canberra, Australia

Oral Presentation The Australian Competition and Consumer Commission (ACCC) has been assessing the safety of lithium-cell button batteries since August 2010. Part of this assessment compared the Australian injury experience with published USA data. This confirmed a similar level and nature of injuries in both countries. The study included an Australian market survey of these batteries and their packaging. Suppliers were consulted for safety information. The survey revealed that some packaging allowed easy access by children to multiple batteries. However, some batteries were individually packaged within an all-plastic seal that made access by children more difficult. The warnings on the packaging also varied. Some warnings detailed the hazards associated with ingestion by small children whereas other products had no relevant warnings or focused solely on disposal of the product after use. The security of battery compartments in products most commonly known for using button batteries was also surveyed. The top two products identified with unsafe battery compartments were LED candles and bathroom scales.

The survey also revealed that while remote controls were often powered by button batteries, these compartments were predominantly secured. The ACCC is also monitoring current standards development work. At this stage it appears that some products such as bathroom scales will not be captured in Australia by current standards development efforts. In April 2012 